\title{
موقع حرية النعبير في مشروع دستور إقليم كوردستان-العراق (دراسة تحليلية مقارنة)
}

هيرش رسول مراد'

'الجامعة التقنية السليمانية، إقليم كوردستان، العراق

\section{المستخلص}

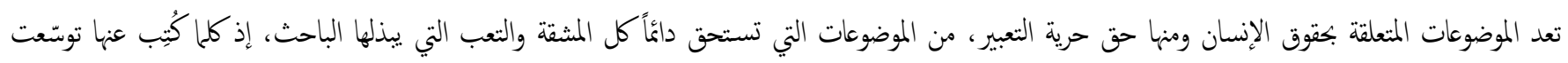

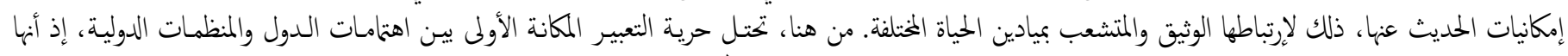

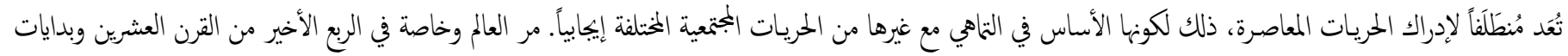

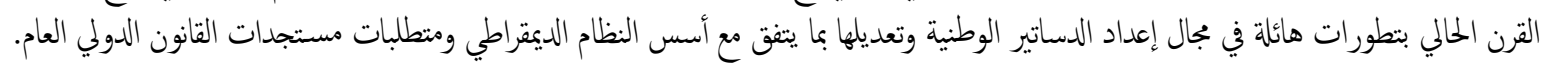

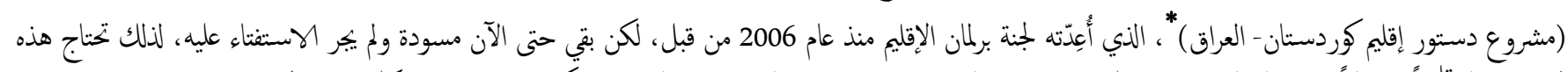

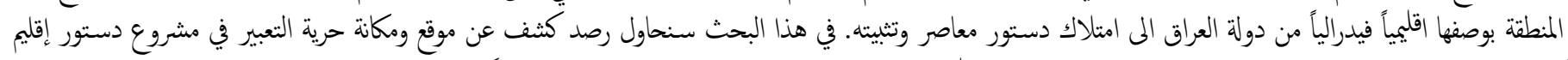

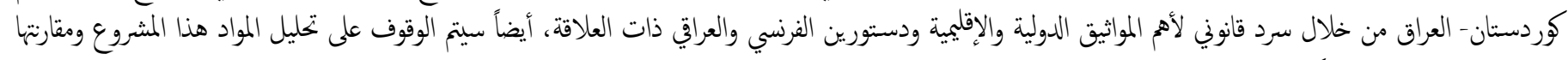
بتاك المواثيق والدساتير المذكورة.

مفاتيح الكلمات: الدستور، حرية التعبير، إقليم كودستان، حقوق الانسان، الدساتير العالمة.

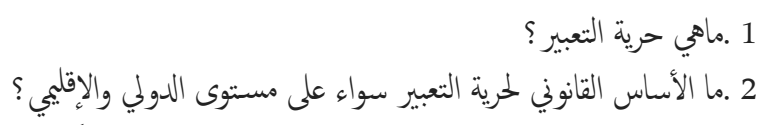

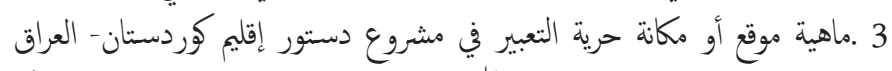

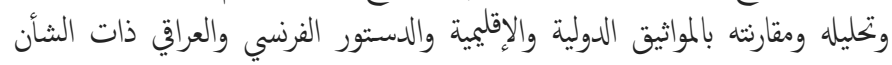
بحرية التعبير.

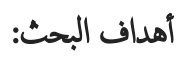
مهدف البحث المى تحقيق ما يأتي: 1 2 .الكشف عن الأساس القانوني لحرية التعبير سواء على المستوى الدولي أم الإقليمي.

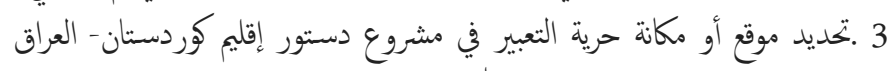
وتحليله ومقارنته بالمواثيق الدولية والإقليمية والدستور الفرنسي والعراقي ذاتي ذات الشأن

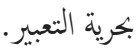

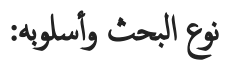
يعدّ هذا البحث من البحوث الوصفية التي عولجت عن طريق البحت استخدام أسلوبي

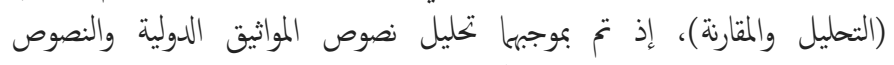

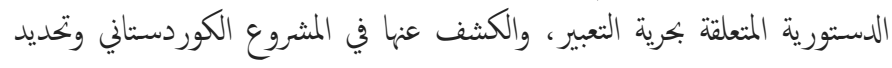

\section{1 - n}

أهمية البحث: يستمد هذا البحث أهميته من أهمية موضوعه المتعلق بحقوق المواطن

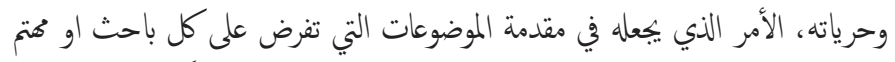

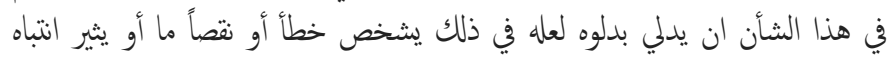

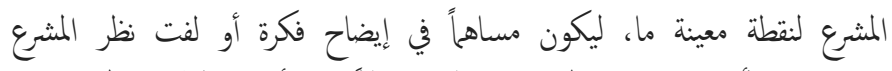

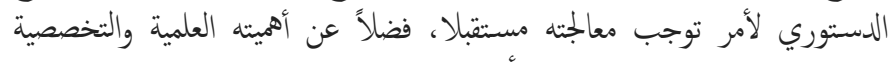

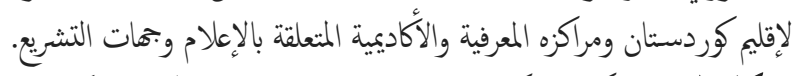

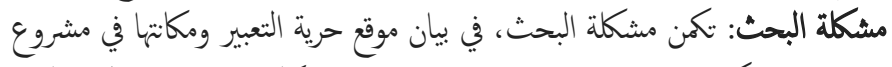

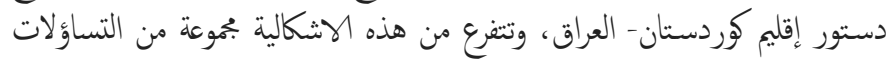

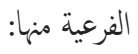

المؤتر العلمي الدولي الثاني لقسم القانون، فاكلتي العلوم الإنسانية و الاجتاعية، جامعة كوية تحت عنوان:

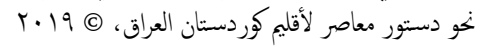

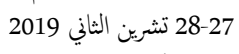
البريد الإلكتروني للمؤلف الوول: hersh.rasool@spu.edu.iq

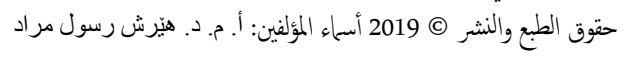


ومن ناحية اخرى فان هناك من يرى ان الدستور هو عبارة عن قانون الحرية.

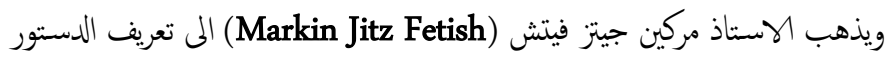

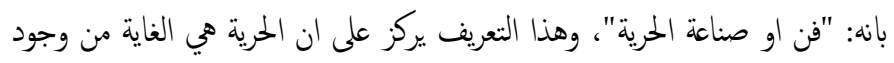

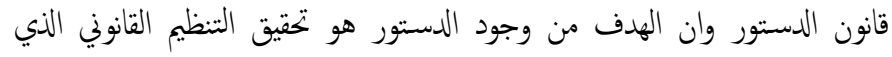
يضمن تفعيل الحرية وإعالها وتقييد السلطة للحؤول دون دون العنور الإعتداء عليها." (كريم،

1987، صن صنم:37.

\section{1-2 أقسام الحرية 1987،}

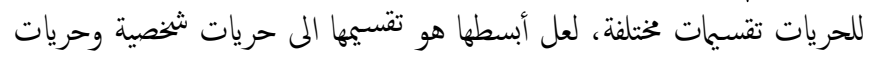

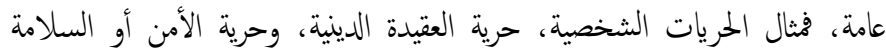

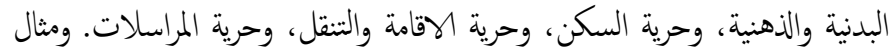

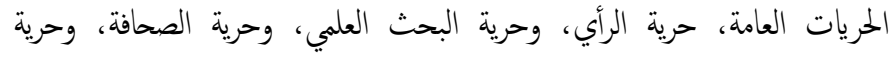

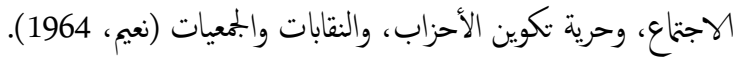

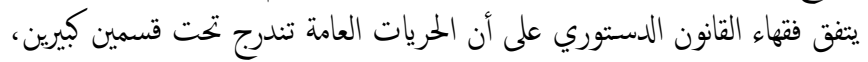

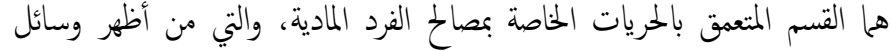

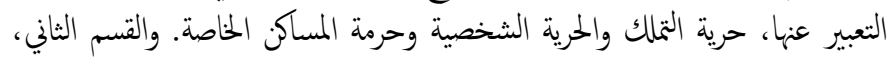

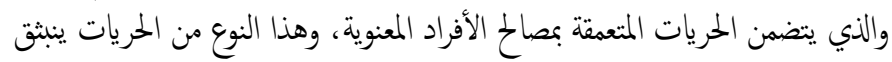

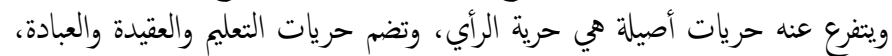

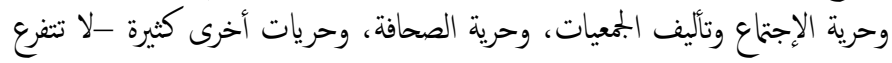

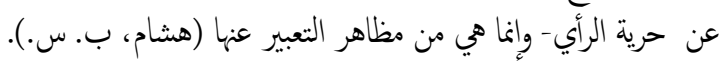

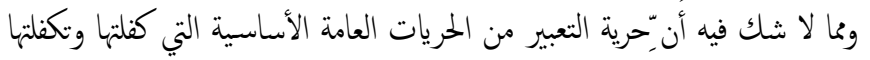

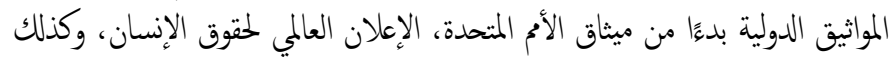

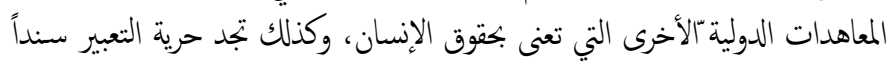

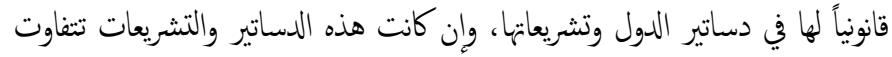

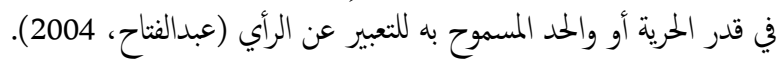

\section{1-3: مفهوم حرية التعبير وتعريفها}

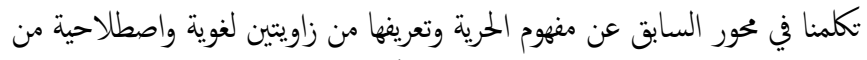

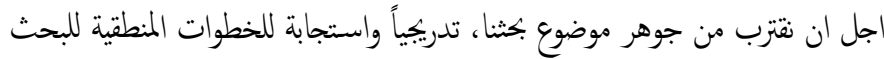
نتطرق، في هذا المحور الى مفهوم حرية التعبير وتعريفها.

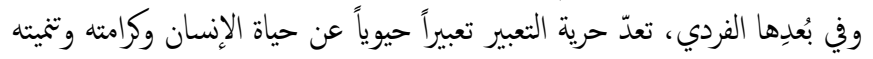

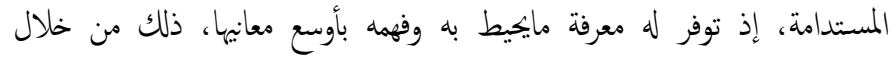

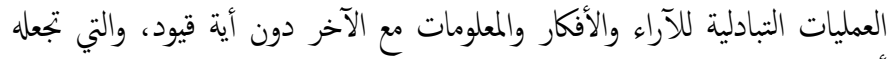

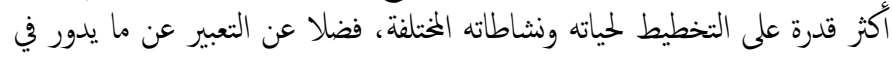

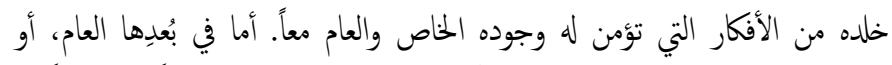

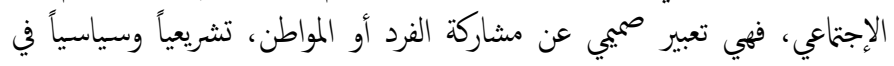

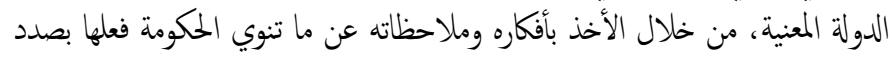

$$
\text { مايجري في المجتع، وخصوصاً المصيرية منها. }
$$

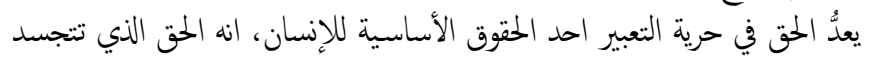

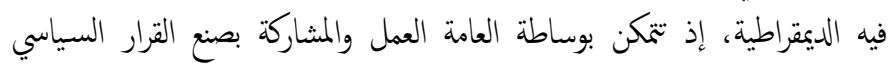

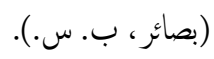

تعد حرية التعبير (Freedom of Expression) أرثاً إنسانياً لكل أبناء المعمورة،

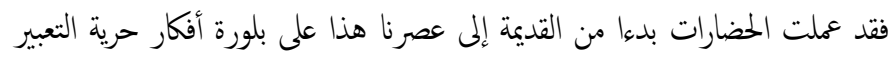

بنودها، مستهدفاً مقارتتها بما يوجد منها في غيره من المواثيق الدولية والإقليمية والدساتير التي سبق تحديها. مجتمع البحث وعينته:

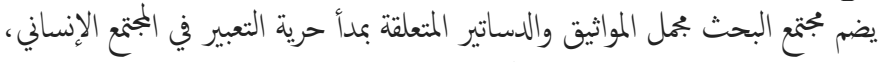

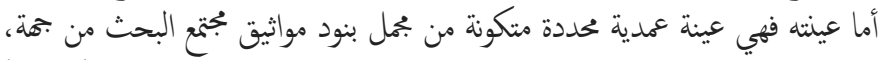

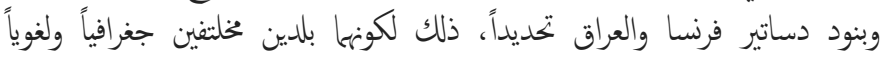

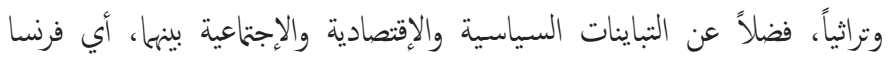

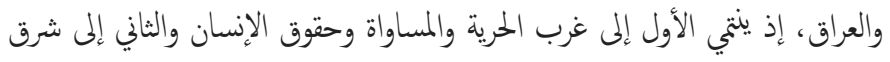

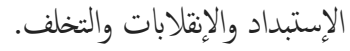

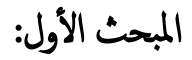 مفهوم حرية التعبير وتعريفها}

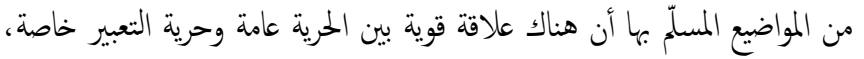

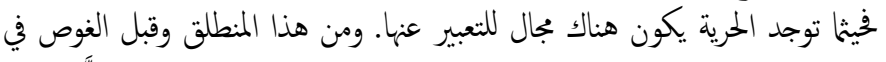

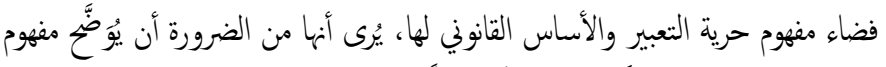

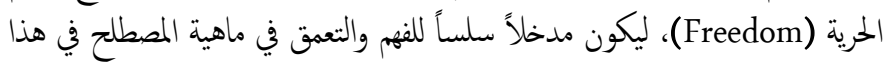
المبحث.

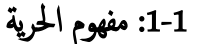

إن عبارة حقوق الإنسان ذات شقين، الشق الأول: يتعلق بالإنسان موضوع الحت.

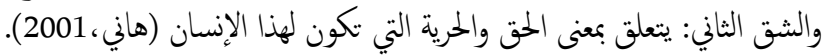

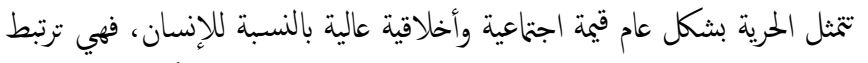

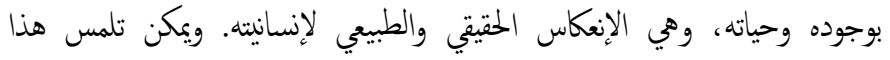

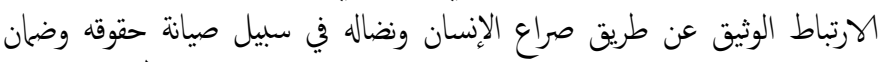

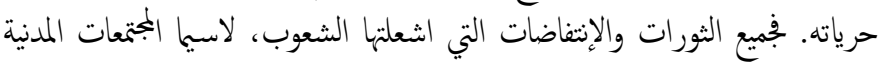

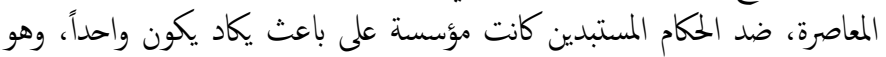

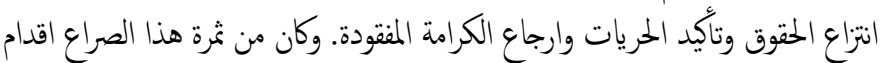

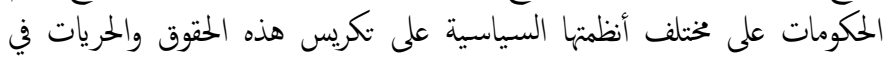

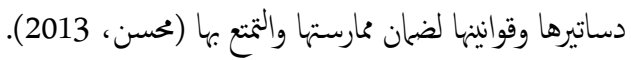

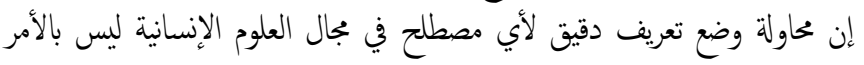

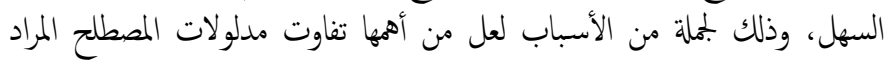

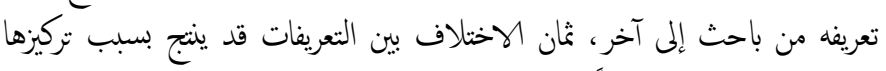

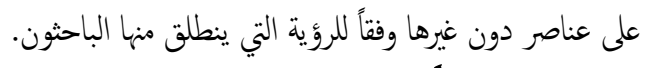

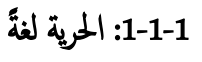

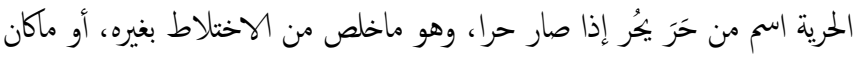

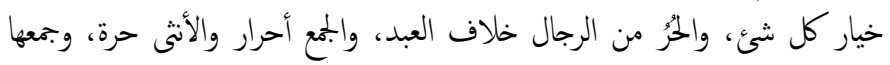

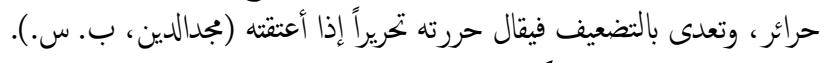

1-1-2

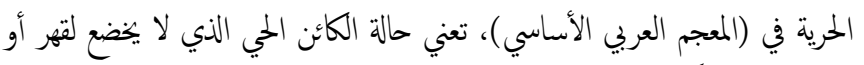

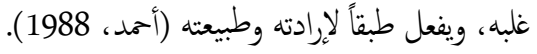

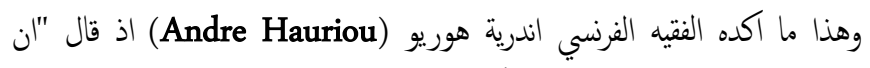
الحرية سلطة، اي قدرة على فعل كل شئ من دون المكان المساس بحرية الاخرين."

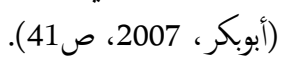




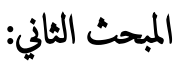 \\ حرية التعبير والأساس القانوفي لها}

بناءً على هذه العلاقة الجدلية للقانون بحرية التعبير، تصح الإثارة إلى المواثيق الدولية والإقليمة والدساتير. ومن ثم تحليل المواد المتعلقة بحرية التعبير.

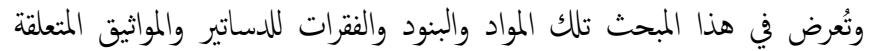

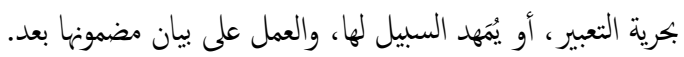

\section{2-12: حرية التعبير في إطار المواثيق الدولية والإقلمية الثية}

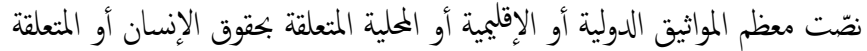

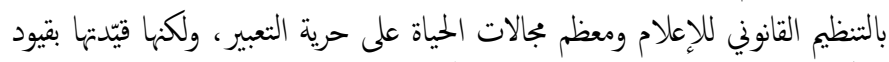

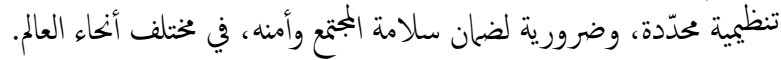

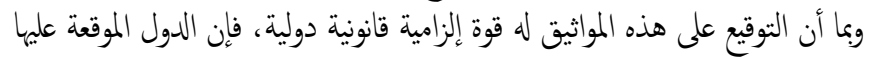

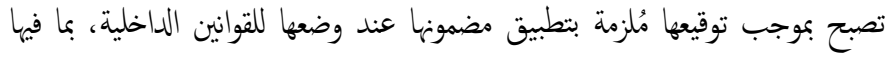
قوانين تنظيم حرية التعبير.

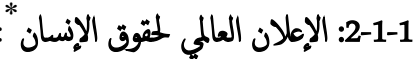

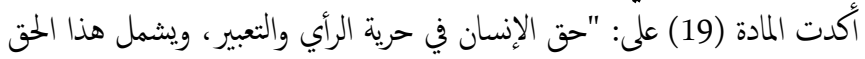

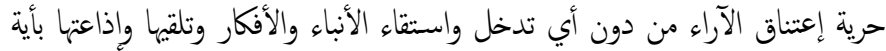

$$
\text { وسيلة كانت من دون تقييد بالحدود". }
$$

\section{|2-1-2 العهد الدولي الحاص بالحقوق المدنية والسياسية":}

كما أكدت المادة 19 على: "1. لكل إلى إنسان حق في اعثناق الآراء من دون مضايقة.

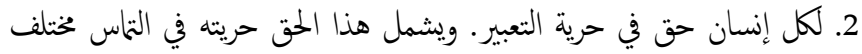

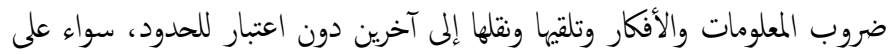
شكل مكتوب أم مطبوع أم في قالب فني أم بأية وسيلة أخرى يختارها.

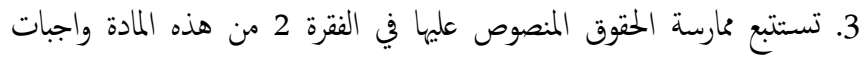

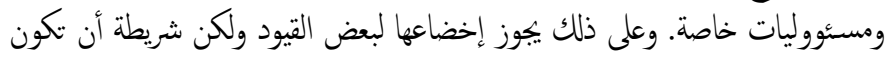

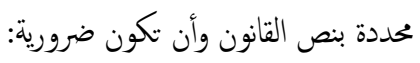
ألماحترام حقوق الآخرين أو سمعتهم.

ب. لمحاية الأمن القوبي أو النظام العام أو الصحة العامة العامة أو الآداب العامة".

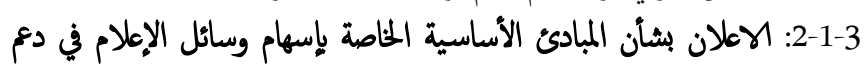
السلام والثغام الدولي، وتعزيز حقوق الإنسان*: تشير المادة (2) الى: الى "1. إن معارسة حرية الرأي وحرية التعبير وحرية الإعلام، المعترف بها بوصنها جزواً

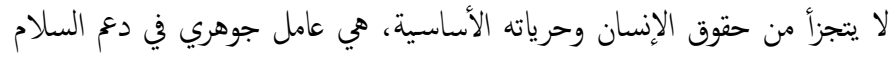
والثفام الدولي.

2. يجب ضان حصول الجمهور على المعلومات عن طريق تنوع مصادر الإعلام

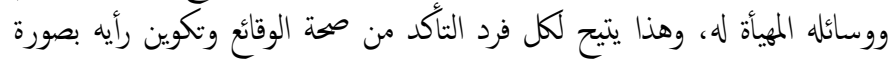

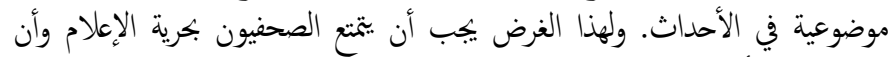

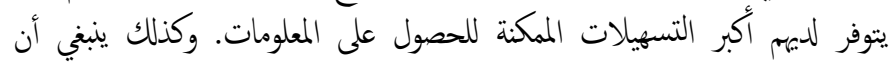
تستجيب وسائل الإعلام لاهتمامات الشعوب والأفراد، هميأة بذلك مشاركة الجمهور في المكات

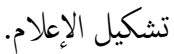
3. عملا علي دع السلام والثفاهم الدولي، وتعزيز حقوق الإنسان، ومكافحة العنصرية

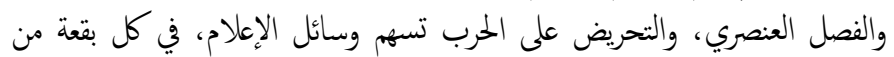

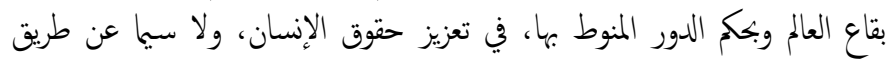

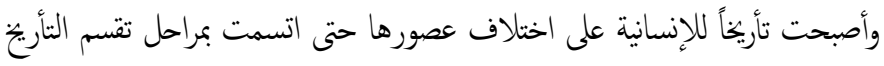

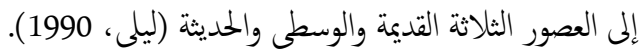

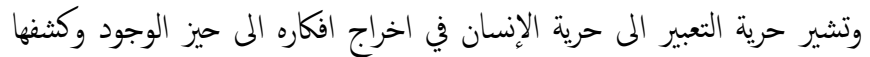

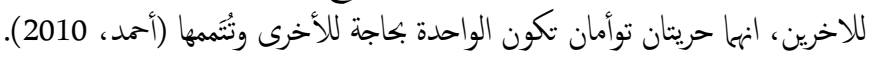

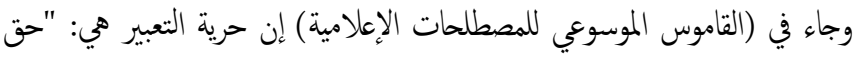

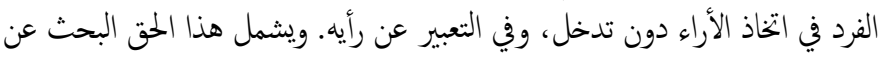

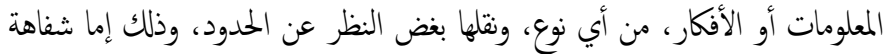

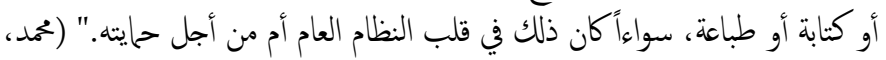

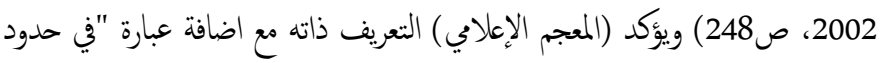

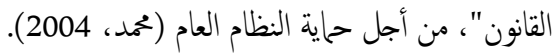
ويكن تعريف حرية التعبير بصفة عامة بأنها- حق الأفراد في التعبير الحر عا يعتنقونه

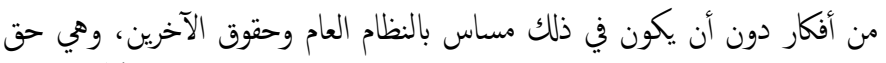

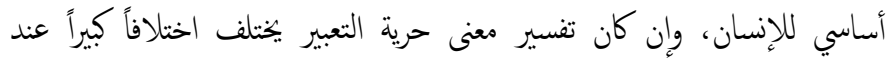

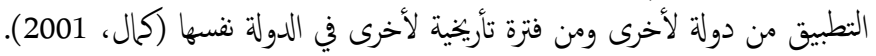
ويشير مصطلح حرية التعبير، الى العديد من المفاهيم التي منها: حرية الرأي العالي والإعلام

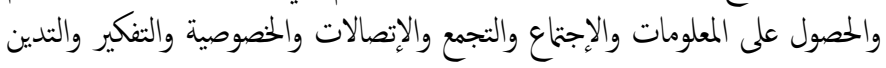
والتعليم وغيرها.

\section{1-4: 1- عناصر حرية التعبير}

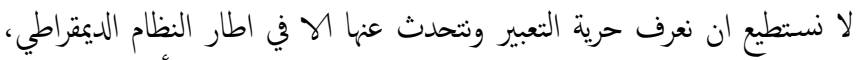

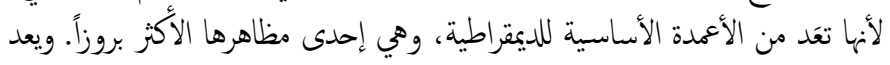

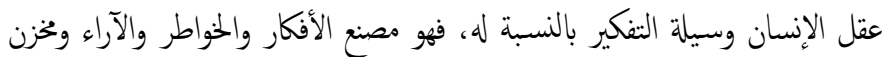

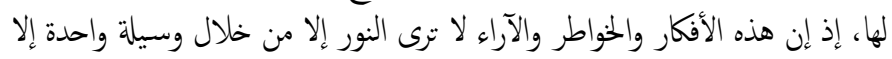

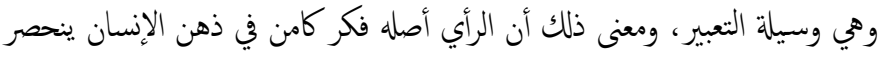
داخل النس (عبدالميد، 1945).

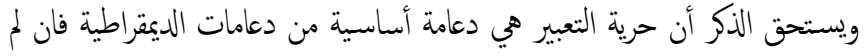

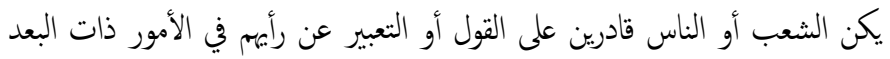

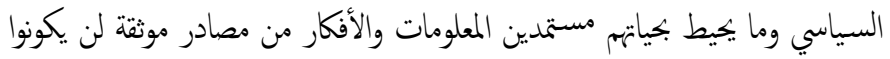

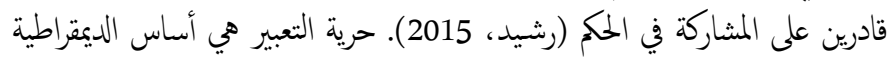
(Michel Verpeaux, 2010)

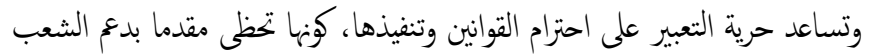

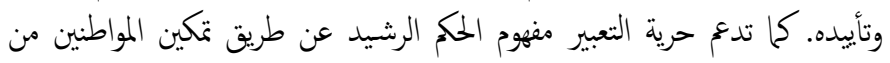

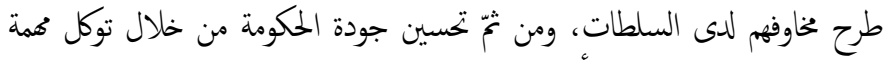
إدارة الدولة إلى الأشخاص الأكثر كفاءة ونزاهة.

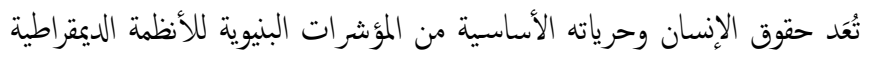

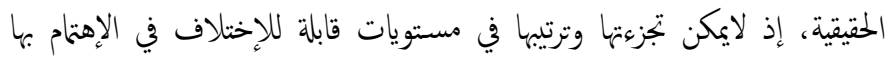

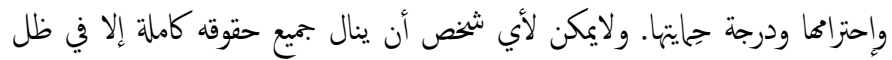

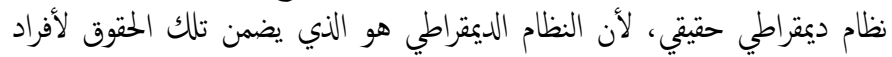

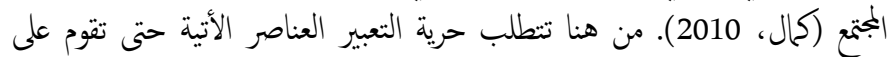

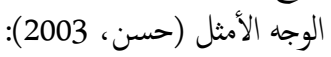
أ. الإيمان الراسيخ بالعقل الذي يألَف المناقشة والحوار والجدل. ب. ب. إنسار الحصانة عن أي فرد في الجنتع. ج· وجود بيئة تتسم بالتسامح تسود فيها حرية التعبير والرأي. 


\section{ت-1-2-2: الميثاق العربي لحقوق الإنسان :}

تشير مادة (32) الم: المرئ

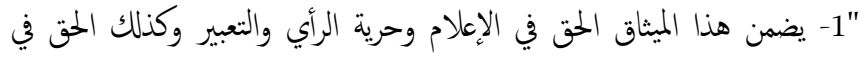

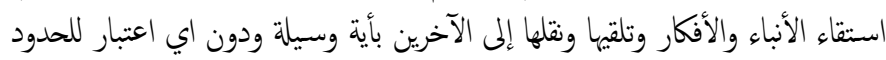

الجغرافية.

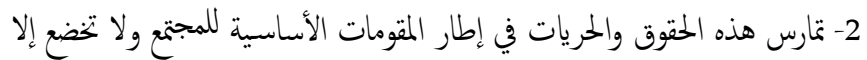

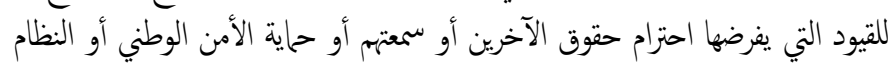

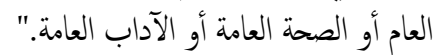

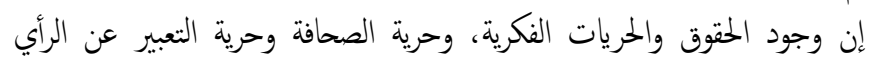

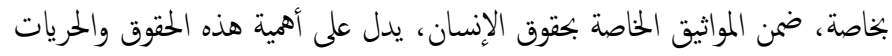

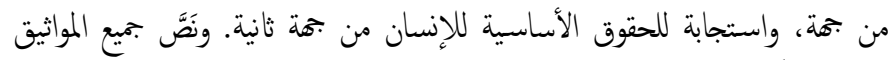

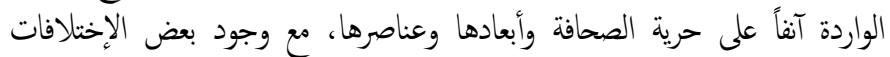

الطفيفة حول بيان مضمونها (هيرش، 2016).

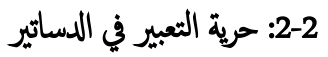

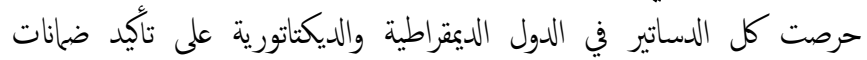

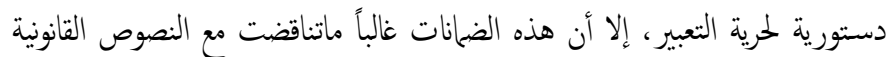

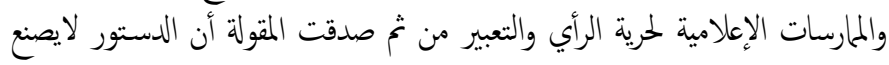

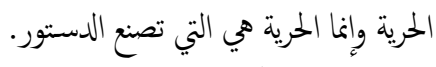

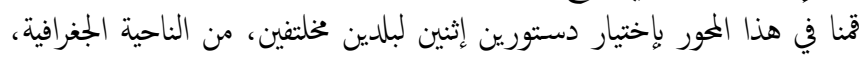

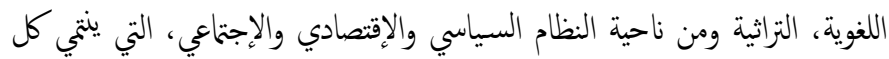

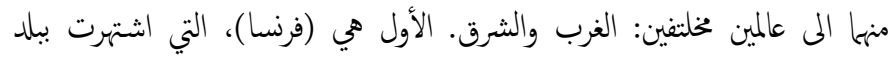

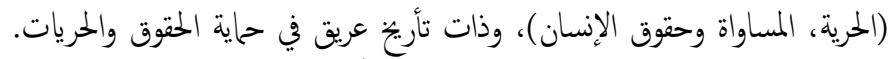

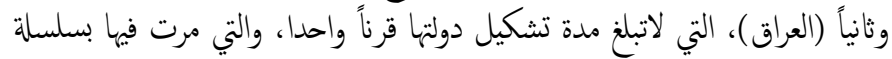

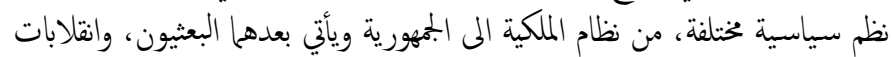

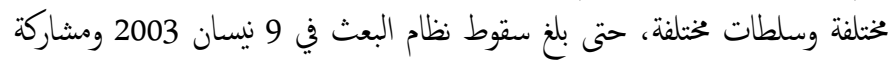

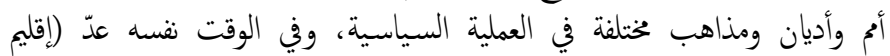
كوردستان) كإقليم فيدرالي والإعتراف بها.

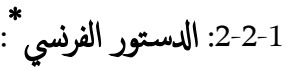

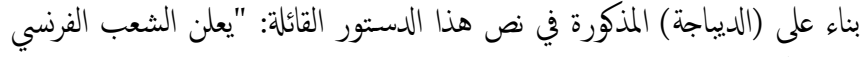

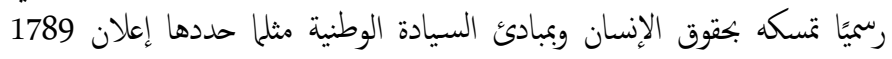

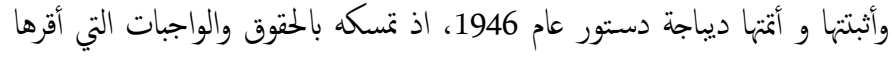

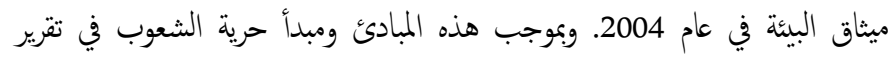

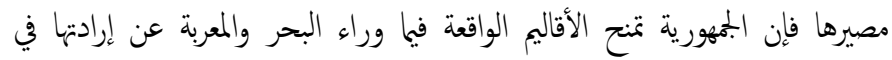

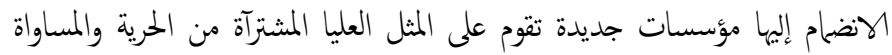

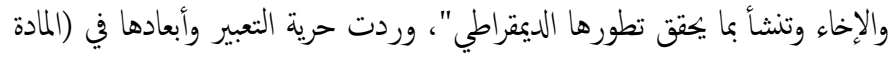

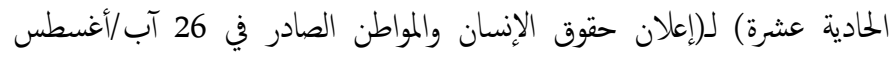
1789)، كما هي:

"حرية التعبير عن الأفكار والآراء هي واحدة من أغلى حقوق الإنسان بها يستطيع

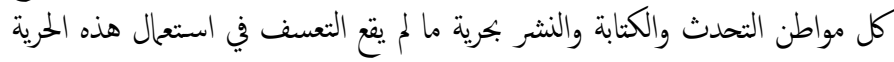
وفقا للحالات التي يحددها القانون".

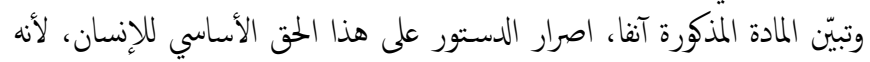

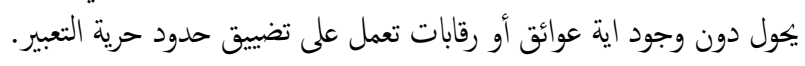

إسماع صوت الشعوب المقهورة التي تناضل ضد الاستعار والاستعار الجديد

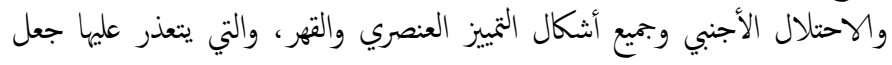
صوتها مسموعا في بلادها. 4. ولكي تتمكن وسائل الإعلام من تعزيز مبادئ هذا الإعلان في ممارسة أنشطتها، لا لا

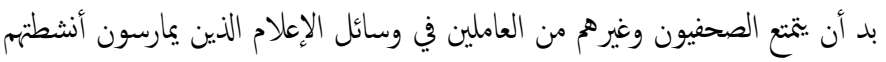

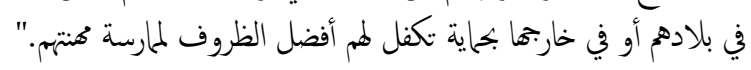

2-1-2-1 الاثفاقية الأوروبية لمحاية حقوق الإنسان والحريات الأساسية :

$$
\text { تنص المادة (10) على: "حرية التعبير }
$$

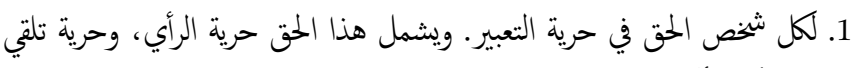

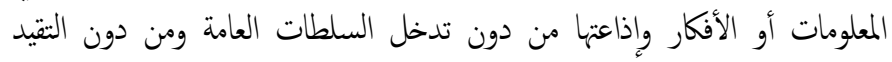

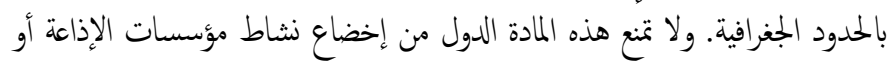
السينما أو التلفزة لطلبات الترخيص.

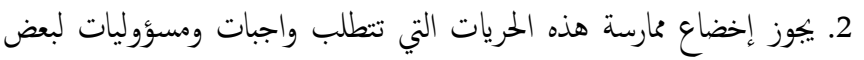

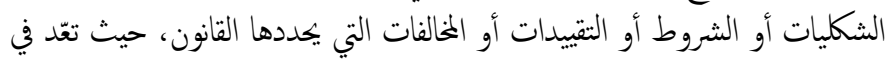

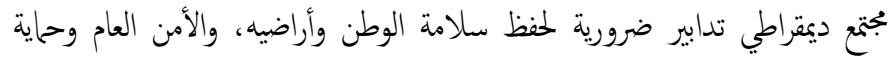

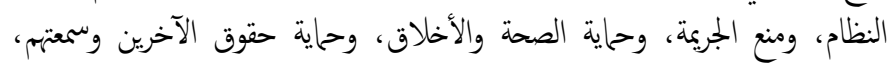

وذلك لمنع إفشاء المعلومات السرية، أو ضمان سلطة الهيآة القضائية ونزاهتها".

\section{2-1-5: الإثفاقية الأمريكية لحقوق الإنسان :} جاءت في مادة (13): حرية الفكر والتعبير: الإنية

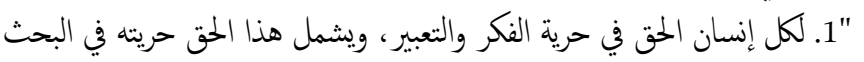

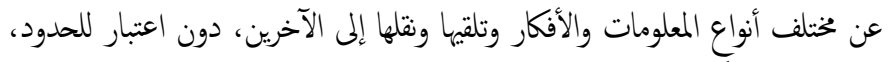

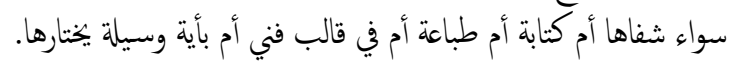

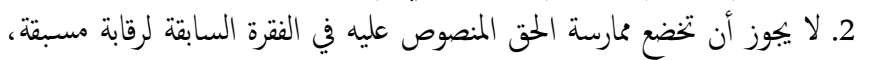

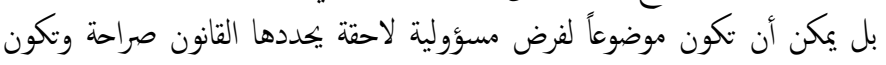

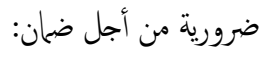
أ- احترام حقوق الآخرين أو سمعتهم.

ب- باية الأمن القومي أو النظام العام أو الصحة العامة ألعام أو الأخلاق العامة.

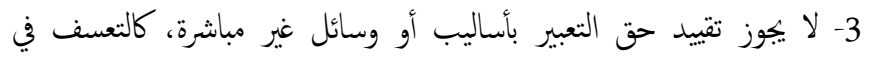

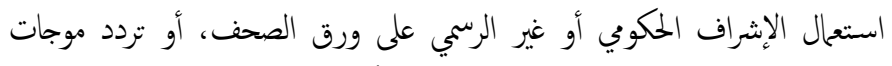

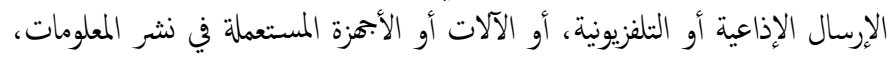

أو بأية وسيلة أخرى من شأهها أن تعرقل نقل الأفكار والآراء وتداولها والأل الأنتشارها.

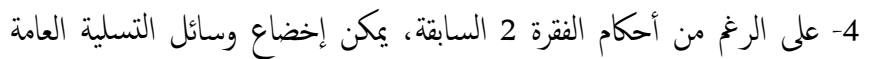

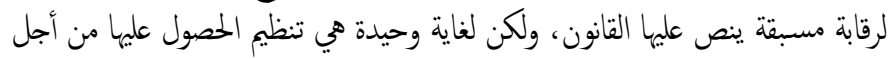
المحاية الأخلاقية للأطفال والمراهقين.

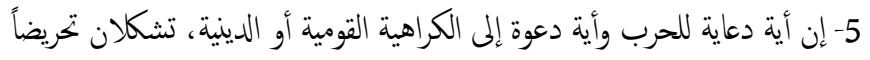

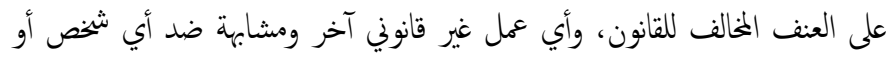

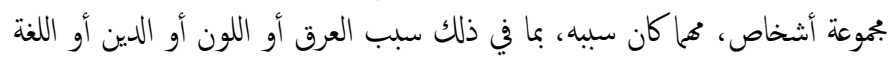
أو الأصل القومي يعد جريمة يعاقب عليها القانون."

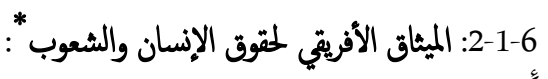

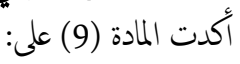
"1. من حق كل فرد ألمادة (و) علن أن يحصل على المعلومات.

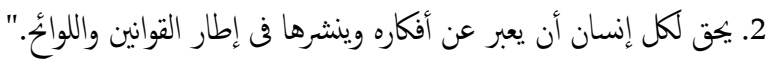


يتولى الدستور أيضا تنظيم موضوع الحقوق والحريات الفردية سواء كانت هذه المهاء

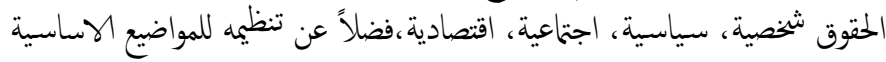

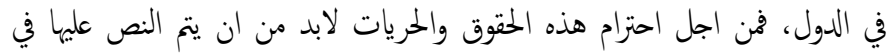

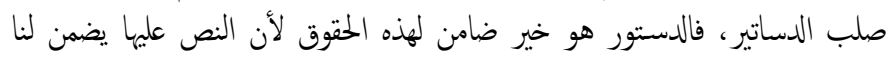

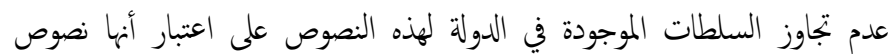

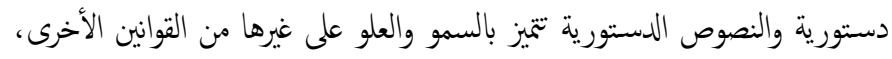

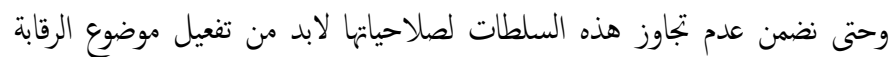

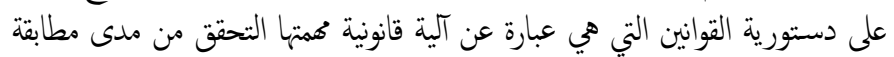

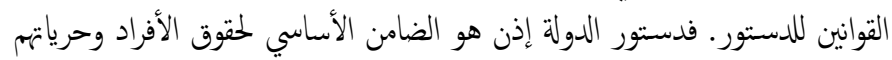

(وسن، 2013).

\section{3-2: واقع اقليم كوردستان- العراق وضرورة صياغة دستور معاصر له:}

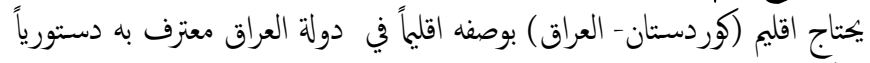

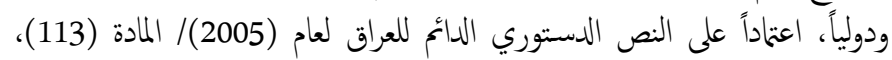
يجتاج إلى صياغة وتثبيت دستور معاصر.

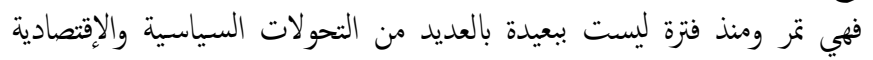

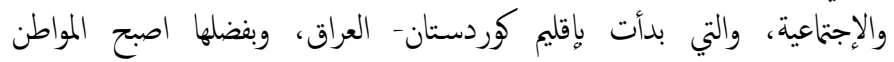

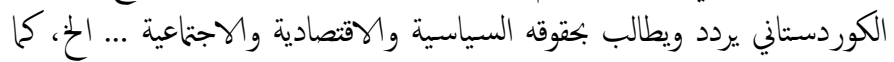

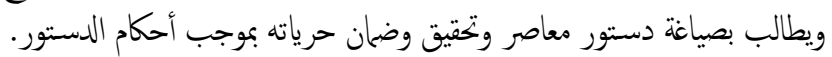

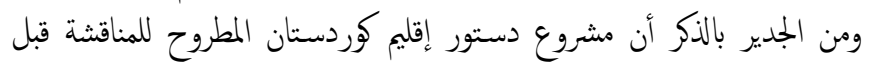

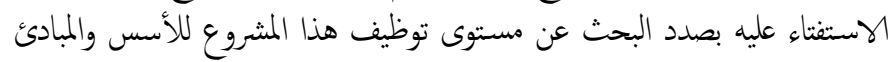

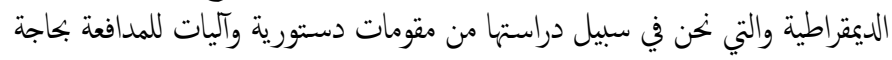
الى الخدمة لتعزيز المشروع والرفع من شأنه.

3-3: مشروع دستور إقليم كوردستان- العراق * : وجاء في (المادة 19): "الكرامة والحياة والحرية:

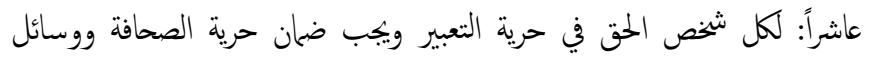

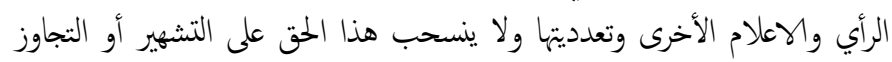

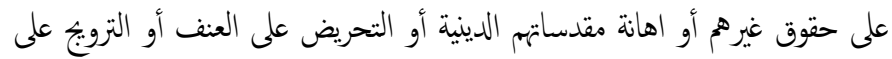

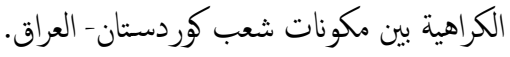
حادي عثر: يضمن حق الحصول على المعلومات بقان بانون."

\section{4-3: تحليل حرية التعبير في المشروع ومقارته بالموائيق والدساتير المذكورة:}

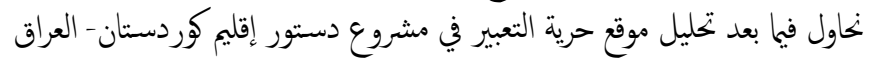

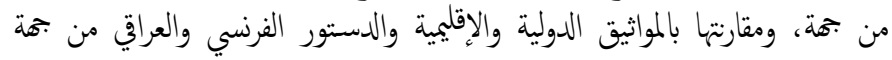
الأخرى. أنّ مشروع دستور إقليم كوردستان - العراق يكتنفه بعض النقص والقصور فيا

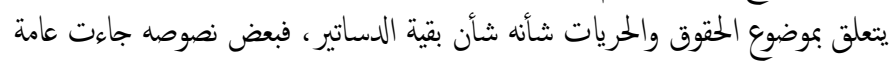

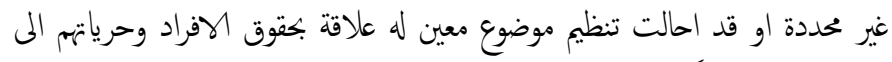

قوانين تصدر لاحقاً.

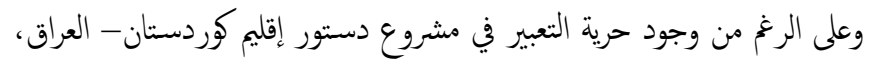

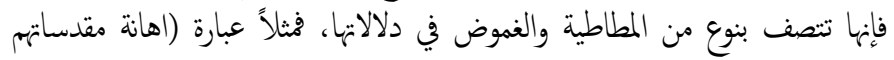

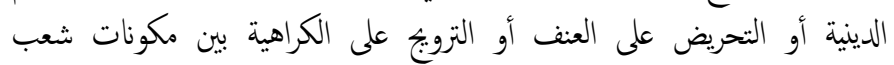

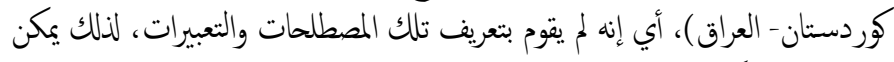

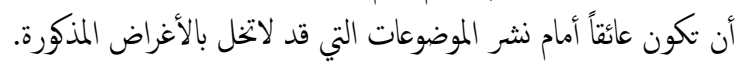

يعدّ دستور فرنسا من اهم الدساتير العالمية التي تناولت بالتفصيل كل المبادئ

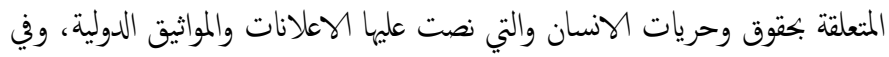

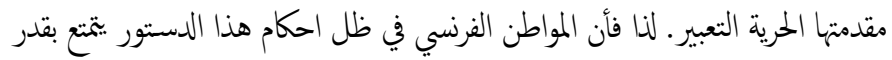

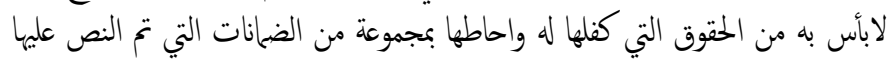
صراحة.

وجاء :2-2-2 الدستور العراقي :

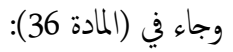
"تكفل الدولة، بما لا يخل بالنظام العام والآداب: أولاً: حرية التعبير عن الرأي بكل الوسائل.

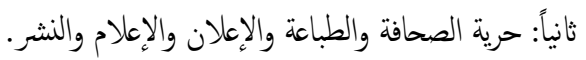

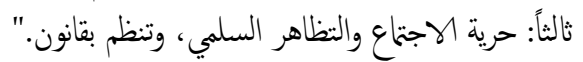

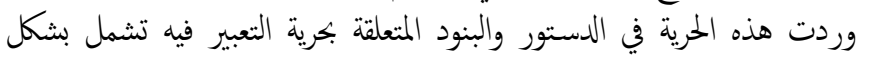

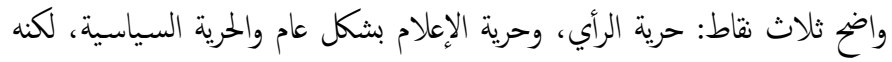
قام بتقييد تلك الحريات بحاية (النظام العام، الآداب). المبحث الثالث:

\section{موقع حرية التعبير في مشروع دستور إقليم كوردستان- العراق 1-13: الدستور وضانه اللحقوق والحريات:}

تعرف الأنسكوبيديا الأكاديمية الأمريكية (3) American (Encyclopedia

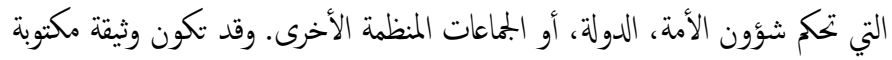

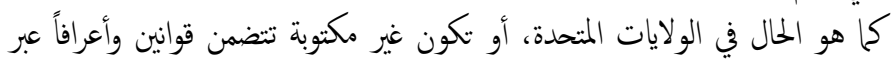

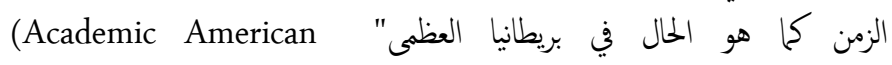
.Encyclopedia, 1981, p212) من البدهيات في النظم الديمقراطية تثثيل الدستور اللوثيقة القانونية العليا في الدولة

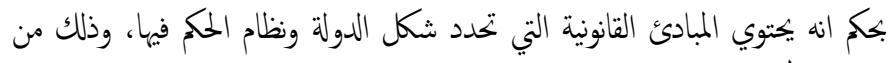

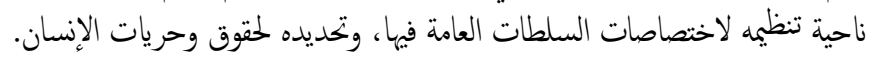

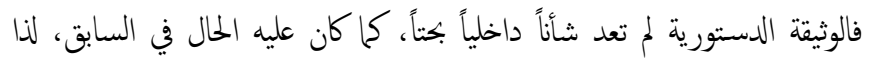

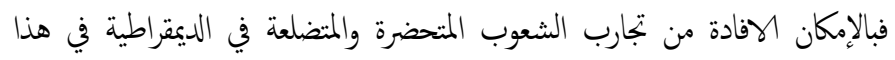

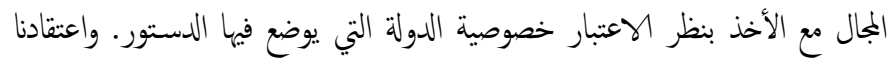

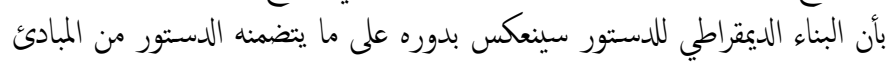

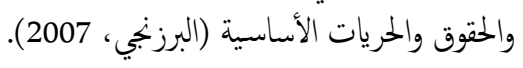

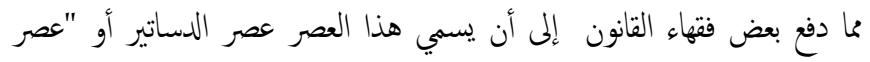

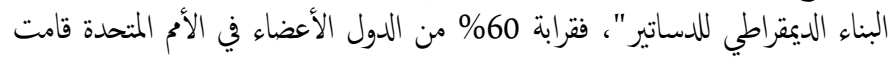

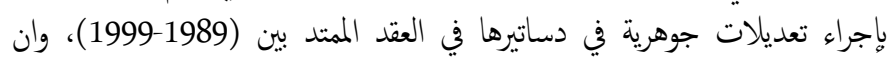

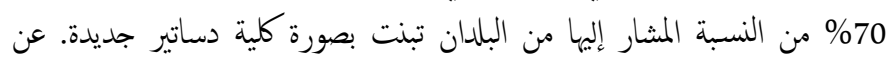

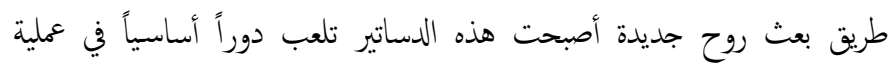

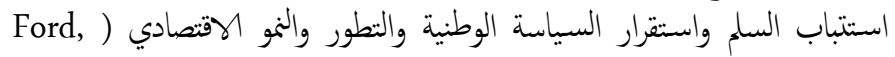
(2004

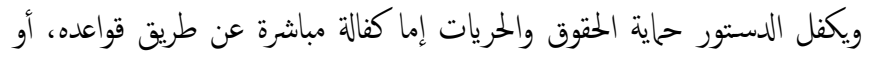

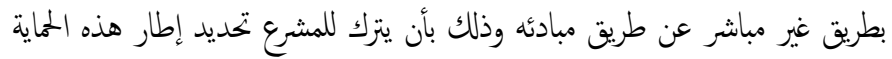

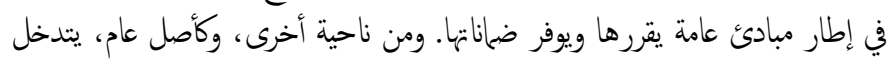
المشرع لتنظيم الحقوق والحريات (أحمد، 2000). 
4. عدم وجود الواجبات والمسؤوليات المنصوص عليها في المواثيق الدولية والإقليمية والدستورين الفرنسي والعراقي في مشروع الإقليم.

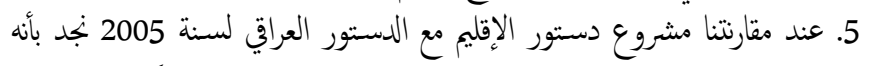

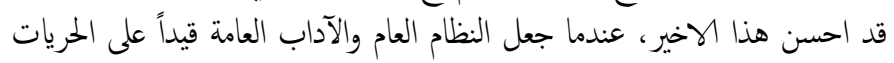

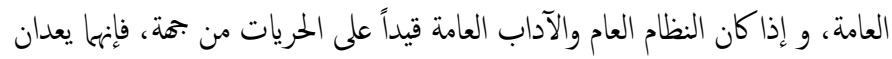

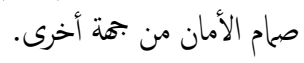
6. ورود بعض المصطلحات والتعبيرات في مشروع الإقليم بشكل مطاطي وغامض. الثاني: التوصيات في ضوء النتائُ والاستناجات التي توصل إلهيالبحث يمكن تسجيل التوصيات الآتية:

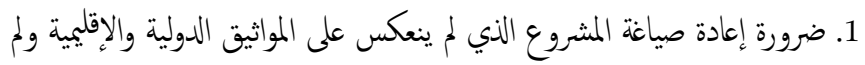

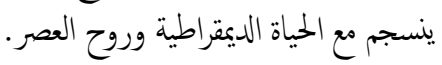
2. ضرورة اشتمال هذا المشروع لحرية التعبير في كافة مجالاتها وعناصرها.

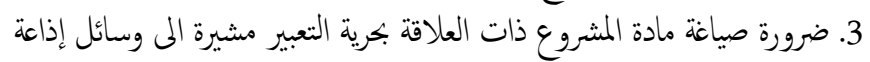
هذه الحرية وحدودها الجغرافية.

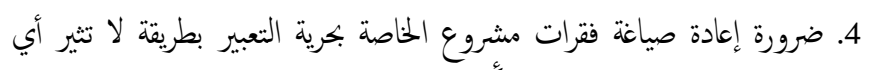
لبس أو غموض ، وعدم تحميل النص بأكثر من معني في كافة نواحيه. الثالث: المتزرحات يقتح الباحث بعد تقديم الاستناجات والتوصيات يأتي:

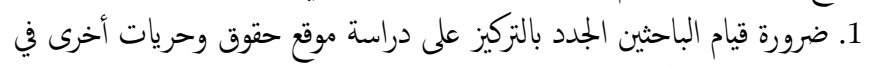
مشروع دستور إقليم كوردستان - العراق. 2. الإهتمام بدراسة إعادة صياغة دستور لإقليم كوردستان - العراق بناءً على المبادئ الديمقراطية وروح العصر.

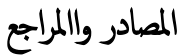

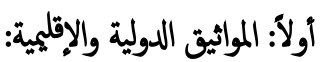

إعلان بشأن المبادئ الأساسية الخاصة بإسهام وسائل الإعلام في دع السلام والتفاهم الدولي، وتعزيز حقوق الإنسان 1978/11/28. لإعلان العالمي لحقوق الإنسان 1948/12/10. العهد الدولي الخاص بالحقوق المدنية والسياسية 1966/12/16. الإتفاقية الأمريكية لحقوق الإنسان 1969/11/22. الميثاق الأفريقي لحقوق الإنسان والشعوب 1981/1/18. الميثاق العربي لحقوق الإنسان 2004/5/23. الاتفاقية الأوروبية لماية حقوق الإنسان والحريات الأساسية 1950/11/4. ثانياً: الدساتير ومشروع الدستور: الدستور العراقي الدائم لسنة 2005. الدستور الفرني لسنة 1958، وتعديله لسنة 2008.
وفي الوقت نفسه انغكست عناصر حرية النعبير في هذا المشروع المى حدما، ولكنها

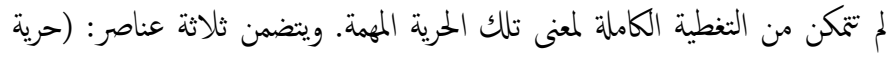
الرأي، وحرية الإعلام، وحرية الوصول إلى المعلومات).

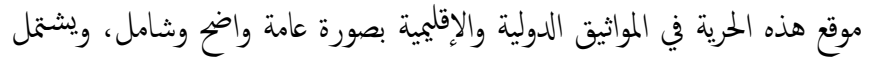

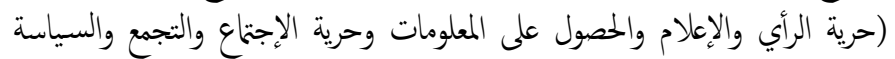

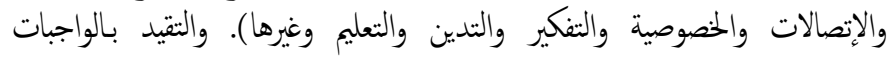

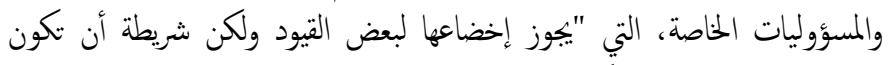

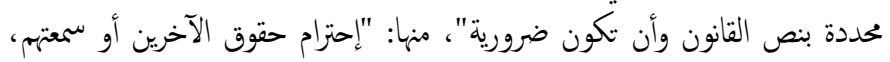

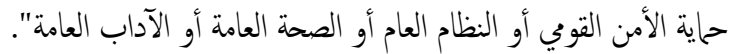

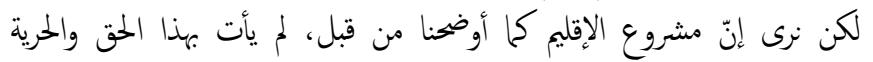
الأساسية بهذا والوضوح والشمول، ولم يذكر عناصرها بكاملها.

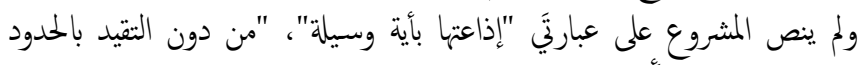

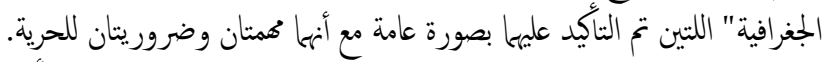

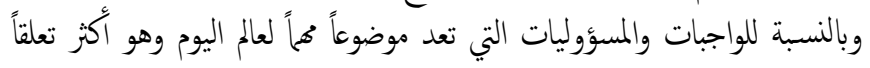

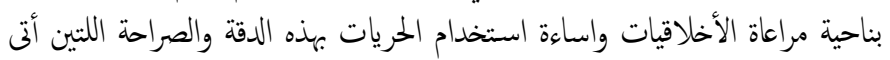

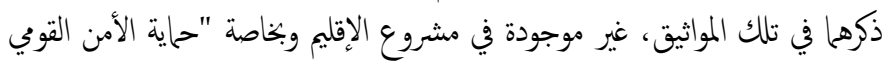

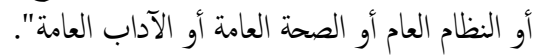

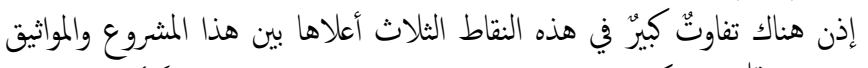

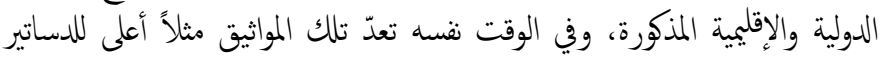
والتشريعات الدولية. وفيما يتعلق بمقارنة مشروع الإقليم بهذين الدستورين اللذين أخذناهيا نماذج، يمكننا

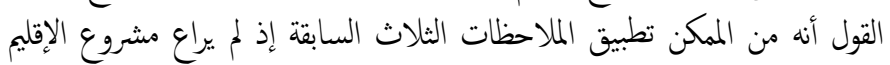
هذه المجالات إلا قليلاً. كما في الوقت عينه إذا ما قارنّا مشروع دستور الإقليم مع الدستور العراقي لسنة الإنة

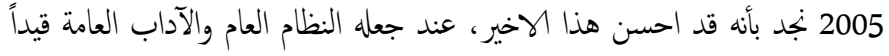

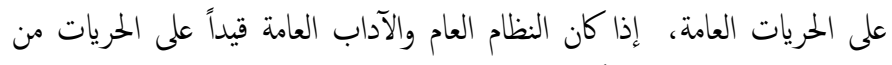

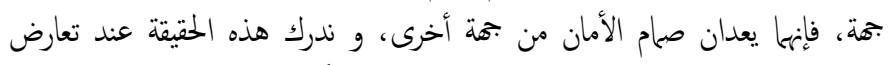

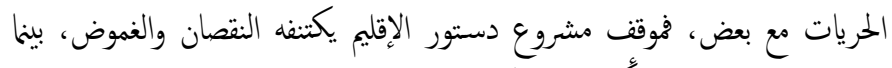
ينسجم موقف الدستور أكثر مع التطور.

الخائمة:

قد اختمت البحث بمجموعة من الإستنتاجات والتوصيات والمقترحات، وذلك النحو

\section{أولاً: الإستناجات}

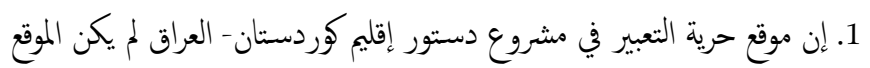

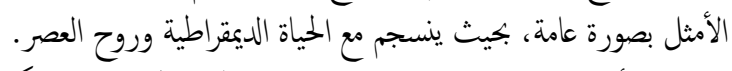

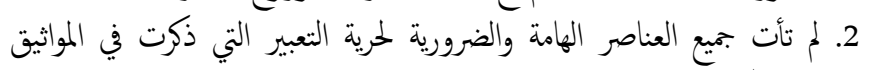

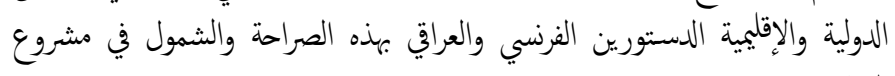
الإقليم. 3. على الرغا من أهمية بعض العبارات المذكورة في المواثيق الدولية والإقليمية

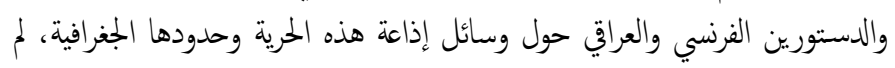
ينص المشروع عليهاً. 


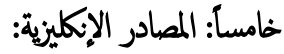

J Ford. The Age of Constitutions, Reflecting on the new faith in federal constitutions. Lessons for the EU, IRAQ, Afghanistan from Australian and other experience- as well as lessons for Australia's own constitutional development. This paper was presented at the National Europe Centre, ANU on 5 MAY 2004. P.1. Available at: file://C:/Users/click/Downloads/The_Age_of_Constitu tions_Reflecting_on_the_new_f\%20(1).pdf.<(15.07.201 9)>.

Michel Verpeaux. Freedom of Expression: In Constitutional and International Case Law. Council of Europe. September 2010. at 30. Available at: http://books.google.iq/books?id=vJptypOd6eUC\&printsec $=$ frontcover $\& \mathrm{dq}=$ fre

edom+of+expression\&hl=en\&sa=X\&ei=1iEQT7K2IqTc4Q ST9emEBA\&redir_e

$\mathrm{sc}=\mathrm{y} \# \mathrm{v}=$ onepage $\& \mathrm{q}=$ freedom $\% 20 \mathrm{of} \% 20$ expression $\& \mathrm{f}=$ false $.<(25.7 .2019)>$.

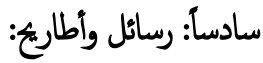

أبوبكر علي محمد أمين: مفهوم العدالة ومنطلقاتها، رسالة ماجستير غير منشورة، الحانة

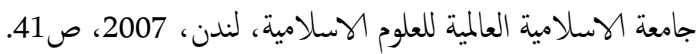

سرهنك حميد صالح البرزيجي: مقومات الدستور الديمقاطي واليات المدافعة

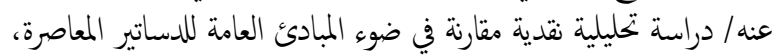

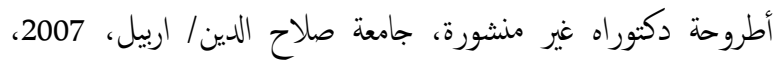

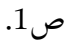

نعيم عطية: مساهمة في دراسة النظرية العامة للحريات الفردية، رسالة دكتوراه

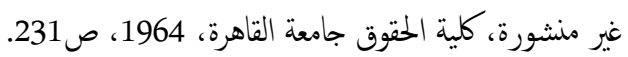

\section{سابعاً: بحوث ودراسات:}

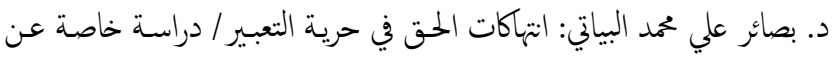

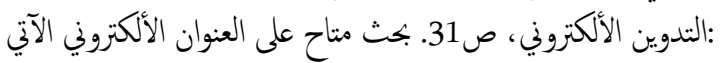

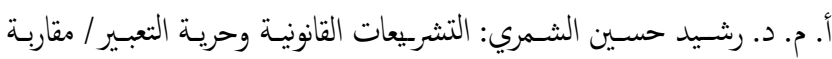

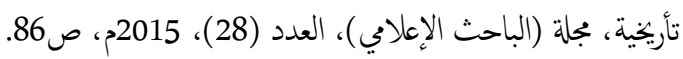

كمال الجوهري: الحدود القانونية لحرية الرأي، التربية مجلة تصدرعن اللجنة الوطنية

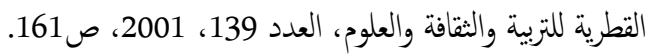

عبدالميد البدوي: حرية القول في مصر-، ججلة مصرـ المعاصرة، ج36، 1945،

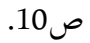

http://erepository.cu.edu.eg/index.php/ARTS-

Conf/article/view/5151<(7.7.2019)>.
مشروع دستور اقليم كوردستان- العراق، صادق عليه برلمان الإقليم في .2009/6/24

ثالثاً: المعابم والقواميس:

أحمد مختار عمر (حرر): المعجم العربي الأساسي، (اليكسو: المنظمة العربية للتربية

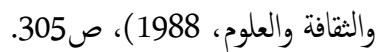

د. محمد فريد عزت: القاموس الموسوعي للمصطلحات الإعلامية (انجليزي-عربي)،

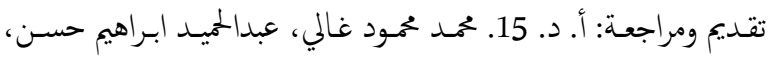

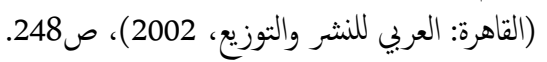

د. محمد منير حجاب: المعجم الإعلاي، (القاهرة: دار الفجر للنشر والتوزيع، 2004)، ص218.

مجدالدين محمد بن يعقوب الفيروز آبادي: القاموس المحيط، الجملد الثاني، (بيروت:

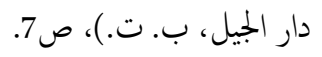

Academic American Encyclopedia. Arete publishing company.vol.5. USA.1981.p.212.

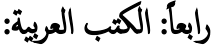

أ. د. حسن عاد مكاوي: أخلاقيات العمل الإعلامي، ط3 (القاهرة: الدار المصرية

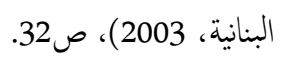

د. أحمد سليم سعيفان: الحريات العامة وحقوق الإنسان ، ج1 (بيروت: منشورات اتحلية الحلبي الحقوقية، 2010)، ص134.

د. أحمد فتحي سرور: المحاية الدستورية للحقوق والحريات، ط2، (القاهرة: دار

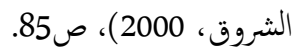

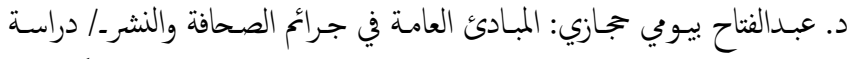
متعمقة عن جرائم الرأي في قانون العقوبات وقانئ المانون الصحافة، (الأسكندرية:

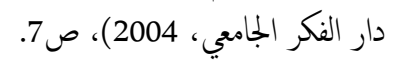

د. كمال سعدي مصطفى: حقوق الإنسان ومعاييرها الدولية، (عمان: دار دجلة، 2010)، ص121.

د. ليلى عبد المميد: الصحافة في الوطن العربي، (القاهرة: العربي للنشر-، عالم

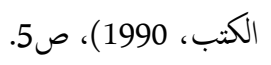

د. هاني سليمان الطعيات: حقوق الإنسان وحرياته الأساسية، (عان: دار

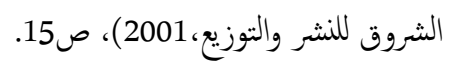

د. هيرش رسول: الوظيفة الرِقابية للصحافة، (بيروت- لبنان: منشورات زين

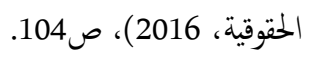

كريم يوسف أحمــ كثـاش: الحـريات العامـة في الأظمهة السياسـية المعاصرة،

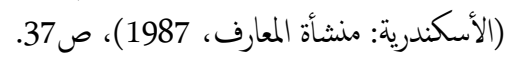

محسن اديب: اثر المواثيق الدولية الماصة بحرية الصحافة في التشريعات الداخلية/

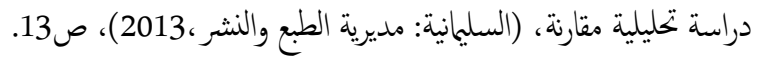


وسن حميد رشيد: الضمانات الدستورية للحقوق والحريات في الدستور العراقي

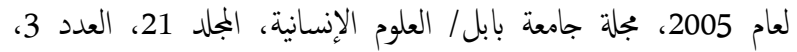

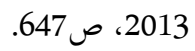

د. هشام بشير: حرية الراي والتعبير في مصر قبل وبعد ثورة 25 يناير، جامعة

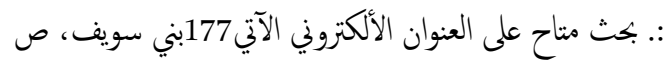

.https://www.iasj.net/iasj?func=article\&aId $=109142$

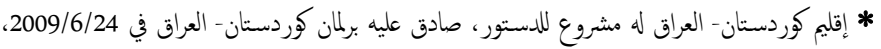

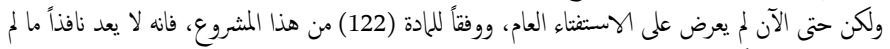

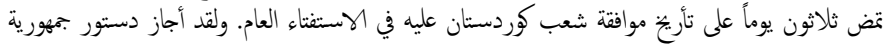

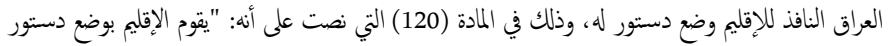

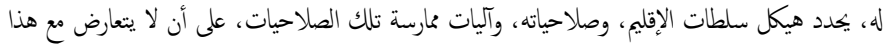
المؤرخ في 16 كانون/ديسمبر 1966. * أصدره المؤتمر العام لمنظمة الأم المتحدة للتربية والعلم والثقافة في دورته العشرين، يوم 28 تشرين الثاني/نوفمبر 1978.

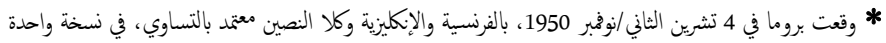

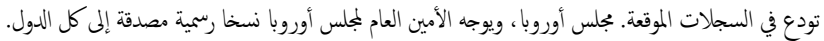

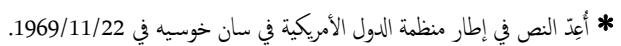
* تمت إجارته من مجلس الرؤساء الأفارقة بدورته العادية رقة 18 في نيروبي (كينيا) يونيو 1981.

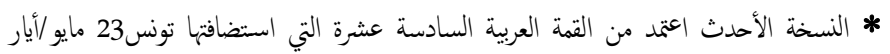
.2004 * الصادر في 4 اكتوبر سنة 1958، وحتى اخر التعديلات التي طرأت عليه في 2004 جويلية سنة .2008 * الذي صوت عليه في 15 تشرين الأول 2005. * أُعِدِ من قبل لجنة اعادة النظر في مشروع دستور اقليم كوردستان -العراق من برلمان كوردستان

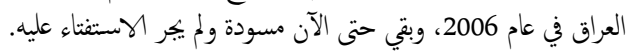

